\title{
Association between cytokine profiles and lung injury in COVID-19 pneumonia
}

\author{
Li-Da Chen ${ }^{1 \dagger}$, Zhen-Yu Zhang ${ }^{2 \dagger}$, Xiao-Jie Wei ${ }^{3 \dagger}$, Yu-Qing Cai ${ }^{4}$, Weng-Zhen Yao ${ }^{4}$, Ming-Hui Wang ${ }^{4}$, \\ Qiu-Fen Huang ${ }^{4}$ and Xiao-Bin Zhang ${ }^{4^{*}}$
}

\begin{abstract}
Background: Coronavirus disease 2019 (COVID-19) is a new respiratory and systemic disease caused by severe acute respiratory syndrome coronavirus 2 (SARS-CoV-2) infection. The purpose of the present study was to investigate the association between cytokine profiles and lung injury in COVID-19 pneumonia.

Methods: This retrospective study was conducted in COVID-19 patients. Demographic characteristics, symptoms, signs, underlying diseases, and laboratory data were collected. The patients were divided into COVID-19 with pneumonia and without pneumonia. $\mathrm{CT}$ severity score and $\mathrm{PaO}_{2} / \mathrm{FiO}_{2}$ ratio were used to assess lung injury.

Results: 106 patients with 12 COVID-19 without pneumonia and 94 COVID-19 with pneumonia were included. Compared with COVID-19 without pneumonia, COVID-19 with pneumonia had significantly higher serum interleukin (IL)-2R, IL-6, and tumor necrosis factor (TNF)-a. Correlation analysis showed that CT severity score and $\mathrm{PaO}_{2} / \mathrm{FiO}_{2}$ were significantly correlated with age, presence of any coexisting disorder, lymphocyte count, procalcitonin, IL-2R, and IL-6. In multivariate analysis, log IL6 was the only independent explanatory variables for $C T$ severity score $(\beta=0.397, p<0.001)$ and $\mathrm{PaO}_{2} / \mathrm{FiO}_{2}(\beta=-0.434, p=0.003)$.

Conclusions: Elevation of circulating cytokines was significantly associated with presence of pneumonia in COVID19 and the severity of lung injury in COVID-19 pneumonia. Circulating IL-6 independently predicted the severity of lung injury in COVID-19 pneumonia.
\end{abstract}

Keywords: Coronavirus disease 2019, Severe acute respiratory syndrome coronavirus 2, Cytokine, Lung injury, Pneumonia

\section{Backgrounds}

In December, 2019, a cluster of patients with "unknown viral pneumonia" were reported in Wuhan, Hubei province, China. Then it was confirmed that the disease was caused by a novel coronavirus which was named severe acute respiratory syndrome coronavirus 2 (SARS-CoV-

\footnotetext{
* Correspondence: zhangxiaobincn@xmu.edu.cn

${ }^{\dagger}$ Li-Da Chen, Zhen-Yu Zhang and Xiao-Jie Wei contributed equally to this work.

${ }^{4}$ Department of Pulmonary and Critical Care Medicine, Zhongshan Hospital, Xiamen University; Teaching Hospital of Fujian Medical University, No. 201, Hubin Nan Road, Siming District, Xiamen, Fujian Province 361004, People's Republic of China

Full list of author information is available at the end of the article
}

2). In March, the World Health Organization (WHO) declared that the outbreak of coronavirus disease 2019 (COVID-19) has become a global pandemic. Up to May 6, COVID-19 has spread to more than 200 countries with over 3600, 000 laboratory confirmed cases around the world and over 250, 000 death cases. The rapid spread of this disease around the world poses a severe threat to global health.

COVID-19 is a new respiratory and systemic illness with multiple organ damage, among which the lung is the main target organ. Post-mortem lung tissue of COVID-19 patients revealed extensive alveolar oedema, proteinaceous exudate, fibrin deposition, and immune 
cell infiltration [1]. Similar to other viral infection disease such as severe acute respiratory syndrome (SARS) and middle east respiratory syndrome (MERS), the cytokine storm was believed to be one of the major mechanisms which contribute to acute lung injury (ALI) and disease development $[2,3]$. A previous study found that intensive care unit (ICU) patients with COVID-19 had higher plasma levels of interleukin (IL)-10, IL-2, IL-7, tumor necrosis factor (TNF)- $\alpha$, IP-10, monocyte chemoattractant protein 1, Macrophage inflammatory protein 1A than those in non-ICU patients with COVID-19 [4]. Another study including 21 COVID-19 cases reported that severe cases had increased IL-2R, IL-6, IL-10, and TNF- $\alpha$ when compared to moderate cases [5]. However, there is no data evaluating the relationship between cytokine status and lung injury in COVID-19 pneumonia patients.

In the present retrospective study, we focused on the relationship between cytokine profiles and lung injury in COVID-19 pneumonia patients. First, we aimed to compare cytokine profiles between COVID-19 patients with pneumonia and without pneumonia. Second, we aimed to evaluate the relationship between cytokine profiles and lung injury assessed by computed tomographic (CT) findings and $\mathrm{PaO}_{2} / \mathrm{FiO}_{2}$ ratio in COVID-19 patients with pneumonia.

\section{Methods}

\section{Patients}

This was a retrospective observational study carried out in Optics Valley Branch of Tongji Hospital. Consecutive discharged patients in Optics Valley Branch of Tongji Hospital treated by Fujian Medical Team aiding Hubei province were enrolled in the study between January 28, 2020 and March 30, 2020. Inclusion criteria were as follows: 1. COVID-19 patients who had clinical symptoms were confirmed by positive SARS-CoV-2 real-time RTPCR results. 2. Patients had completed laboratory data of cytokines. Patients with age less than 18 years old were excluded. This retrospective study was approved by the Ethics Committee of Zhongshan Hospital, Xiamen University. Informed consent was obtained from patients involved before data were collected retrospectively.

\section{Data collection}

The medical records of all COVID-19 patients with positive SARS-CoV-2 real-time RT-PCR results were reviewed. The demographic data, comorbidities, clinical symptoms, signs, first time of laboratory findings during hospitalization, chest CT findings were collected. All data were checked by a team of trained physicians.

\section{Grouping criteria}

COVID-19 patients were classified as mild cases, moderate cases, severe cases, and critical ill cases according to the guidelines for diagnosis and management of COVID-19 (7th edition, in Chinese) released by National Health Commission of China. Mild cases: the clinical symptoms are mild and no pneumonia manifestation can be found in imaging. Moderate cases: patients have symptoms such as fever and respiratory tract symptoms, etc., and pneumonia manifestation can be seen in imaging. Severe cases: adults who meet any of the following criteria: respiratory rate $\geq 30$ breaths $/ \mathrm{min} ; \mathrm{SpO}_{2} \leq 93 \%$ at rest; $\mathrm{PaO}_{2} / \mathrm{FiO}_{2} \leq 300$. Patients with greater than $50 \%$ lesion progression wihin 24 to 48 hours in pulmonary imaging were also defined as severe cases. Critically ill cases: patients who meet any of the following criteria: occurrence of respiratory failure requiring mechanical ventilation; presence of shock; other organ failure that requires monitoring and treatment in the ICU. We further group mild cases as COVID-19 without pneumonia and moderate cases, severe cases, critical ill cases as COVID-19 with pneumonia.

\section{CT severity score}

$\mathrm{CT}$ images were reviewed and scored independently by two respiratory and critical care physicians who were blinded to the clinical information in a consistent manner. CT severity score was evaluated based on the criteria as previously described $[6,7]$. Briefly, each of the five lung lobes was assessed for percentage of the area involved. It was defined as none (0\%), minimal (1-25\%), mild (26-50\%), moderate $(51-75 \%)$, or severe (76$100 \%$ ), with corresponded lobe score of $0,1,2,3$, 4, respectively. A CT severity score was calculated by summing the five lobe scores. The total score ranges from 0 to 20 .

\section{Cytokine measurement}

Blood samples were collected from the patients on admission or the second day after admission. Serum cytokines including IL-1 $\beta$, IL-2R, IL-6, IL-8, IL-10, and TNF$\alpha$ were measured using chemiluminescent immunoassay (CLIA) by Siemens Immulite 1000 analyzer according to the manufacturer's instructions.

\section{Statistical analysis}

Data analyses were performed using SPSS v 22.0 (SPSS Inc., Chicago, IL). Normally distributed, skewed, and categorical data were described using mean $\pm S D$, median (interquartile range), and number (percentage), respectively. Student's t test was conducted for two group comparison when variables were normally distributed; otherwise, the Mann-Whitney test was used. One-way ANOVA test was conducted for multiple group 
comparison when variables were normally distributed; otherwise, the Kruskal-Wallis $\mathrm{H}(\mathrm{K})$ test was used. Chisquare test or Fisher exact test were used to compare categorical variables. Spearman rank test was performed to test correlations between variables. In order to determine the independent predictors of lung injury, stepwise multiple linear regression analysis was performed. All descriptive data not in normal distribution were logtransformed before multivariate analysis. Statistical significance was determined as $p<0.05$.

\section{Results}

\section{Demographic data and clinical signs and symptoms}

A total of 106 COVID-19 patients with 12 mild cases, 69 moderate cases, and 25 severe cases were included. They were further divided into two groups: COVID-19 without pneumonia $(n=12)$ and COVID-19 with pneumonia $(n=94)$. The baseline demographic and clinical data in different groups are presented in Table 1. COVID-19 patients with pneumonia were older and had a higher respiratory rate than COVID-19 patients without pneumonia. The presence of any coexisting disorder and symptom of fever were more common in COVID-19 patients with pneumonia than in those without pneumonia. The comparison of the data among the three groups was also performed. Age, the rate of any coexisting disorder, respiratory rate, and temperature increased, while $\mathrm{SpO}_{2}$ decreased significantly with the aggravation of the COVID-19 severity.

\section{Laboratory data}

The laboratory data in different groups are summarized in Table 2. D-dimer, fibrinogen, and high sensitive $\mathrm{C}$ reaction protein (hs-CRP) were higher in COVID-19 patients with pneumonia than in those without pneumonia. Laboratory data including blood routine, liver injury index, cardiac injury index, and other coagulation index were similar in both groups. The comparison of the data among the three groups showed a positive association between creatine kinase-MB, lactic dehydrogenase, D-dimer, fibrinogen, procalcitonin (PCT), hs-CRP and COVID-19 severity. A negative association between lymphocyte count, hemoglobin and COVID-19 severity was observed. There was a trend

Table 1 The baseline demographic and clinical data in different groups

\begin{tabular}{|c|c|c|c|c|c|c|c|}
\hline & Overall $(n=106)$ & $\begin{array}{l}\text { COVID-19 without } \\
\text { pneumonia/Mild ( } n= \\
\text { 12) }\end{array}$ & $\begin{array}{l}\text { COVID-19 with } \\
\text { pneumonia( } n= \\
\text { 94) }\end{array}$ & $p$-values & Moderate $(n=69)$ & Severe $(n=25)$ & $p$-values \\
\hline Age, years & $52.75 \pm 16.09$ & $43.92 \pm 13.73$ & $53.87 \pm 16.08$ & 0.043 & $51.41 \pm 15.77$ & $60.68 \pm 15.23$ & 0.005 \\
\hline Male sex, n(\%) & $53(50.0)$ & $4(33.3)$ & $49(52.1)$ & 0.220 & $34(49.3)$ & $15(60.0)$ & 0.309 \\
\hline \multicolumn{8}{|l|}{ Coexisting disorder } \\
\hline Any, n(\%) & 25 (23.6) & $0(0.0)$ & $25(26.6)$ & 0.041 & $14(20.3)$ & $11(44.0)$ & 0.007 \\
\hline $\begin{array}{l}\text { Hypertension, } \\
\mathrm{n}(\%)\end{array}$ & $17(16.0)$ & $0(0.0)$ & $17(18.1)$ & 0.108 & $9(13.0)$ & $8(32.0)$ & 0.028 \\
\hline $\begin{array}{l}\text { Diabetes } \\
\text { mellitus, n(\%) }\end{array}$ & $13(12.3)$ & $0(0.0)$ & $13(13.8)$ & 0.169 & $7(10.1)$ & $6(24.0)$ & 0.103 \\
\hline CHD, n (\%) & $2(1.9)$ & $0(0.0)$ & $2(2.1)$ & 1.000 & $1(1.4)$ & $1(4.0)$ & 0.578 \\
\hline COPD, n (\%) & $1(0.9)$ & $0(0.0)$ & $1(1.1)$ & 1.000 & $1(1.4)$ & $0(0.0)$ & 1.000 \\
\hline \multicolumn{8}{|l|}{ Symptoms } \\
\hline Fever, n (\%) & $56(52.8)$ & $3(25.0)$ & $53(56.4)$ & 0.040 & 37 (53.6) & $16(64.0)$ & 0.082 \\
\hline Cough, n (\%) & $52(49.1)$ & $5(41.7)$ & $47(50.0)$ & 0.587 & $34(49.3)$ & $13(52.0)$ & 0.839 \\
\hline $\begin{array}{l}\text { Sputum } \\
\text { production, n } \\
(\%)\end{array}$ & $14(13.2)$ & $1(8.3)$ & $13(13.8)$ & 0.596 & $7(10.1)$ & $6(24.0)$ & 0.179 \\
\hline Fatigue, n (\%) & $20(18.9)$ & $0(0.0)$ & $20(21.3)$ & 0.076 & $13(18.8)$ & $7(28.0)$ & 0.124 \\
\hline Dyspnea, n (\%) & $7(6.6)$ & $0(0.0)$ & $7(7.4)$ & 0.328 & $3(4.3)$ & $4(16.0)$ & 0.097 \\
\hline \multicolumn{8}{|l|}{ Vital signs } \\
\hline Temperature $\left({ }^{\circ} \mathrm{C}\right)$ & 36.50 (36.30-36.80) & $36.50(36.33-36.60)$ & $36.50(36.30-36.83)$ & 0.270 & $36.50(36.30-36.65)$ & $36.90(36.60-37.70)$ & 0.001 \\
\hline Respiratory Rate & $20.00(20.00-20.00)$ & $19.50(19.00-20.00)$ & $20.00(20.00-20.25)$ & 0.002 & $20.00(20.00-20.00)$ & $20.00(20.00-22.00)$ & 0.001 \\
\hline Heart Rate & $89.89 \pm 13.29$ & $93.17 \pm 14.48$ & $89.47 \pm 13.15$ & 0.366 & $88.94 \pm 13.94$ & $90.92 \pm 10.80$ & 0.545 \\
\hline $\mathrm{SpO}_{2}(\%)$ & $98.00(97.00-98.00)$ & $98.00(97.25-99.00)$ & $98.00(97.00-98.00)$ & 0.174 & $98.00(97.00-99.00)$ & $96.00(93.50-98.00)$ & $<0.001$ \\
\hline
\end{tabular}

Abbreviation: COVID-19 coronavirus disease 2019, CHD coronary artery heart disease, COPD chronic obstructive pulmonary disease, $\mathrm{SpO}_{2}$ pulse oximeter oxygen saturation 
Table 2 The laboratory data in different groups

\begin{tabular}{|c|c|c|c|c|c|c|c|}
\hline & Overall $(n=106)$ & $\begin{array}{l}\text { COVID-19 without } \\
\text { pneumonia/Mild } \\
(n=12)\end{array}$ & $\begin{array}{l}\text { COVID-19 with } \\
\text { pneumonia }(n=94)\end{array}$ & $p$-values & Moderate $(n=69)$ & Severe $(n=25)$ & $p$-values \\
\hline $\begin{array}{l}\text { White-cell count, } \\
\times 10^{9} / \mathrm{L}\end{array}$ & $6.12 \pm 2.29$ & $5.80 \pm 1.46$ & $6.16 \pm 2.38$ & 0.618 & $6.03 \pm 2.17$ & $6.49 \pm 2.92$ & 0.615 \\
\hline $\begin{array}{l}\text { Neutrophil count, } \times \\
10^{9} / \mathrm{L}\end{array}$ & $3.98 \pm 2.14$ & $3.44 \pm 1.16$ & $4.05 \pm 2.23$ & 0.357 & $3.77 \pm 2.02$ & $4.81 \pm 2.64$ & 0.075 \\
\hline $\begin{array}{l}\text { Lymphocyte count, } \\
\times 10^{9} / \mathrm{L}\end{array}$ & $1.50 \pm 0.68$ & $1.78 \pm 0.54$ & $1.46 \pm 0.69$ & 0.128 & $1.59 \pm 0.67$ & $1.12 \pm 0.66$ & 0.003 \\
\hline Hemoglobin, g/L & $128.16 \pm 21.07$ & $132.17 \pm 13.70$ & $127.65 \pm 21.83$ & 0.487 & $130.71 \pm 21.13$ & $119.20 \pm 21.91$ & 0.049 \\
\hline $\mathrm{PLT}, \times 10^{9} / \mathrm{L}$ & $228.16 \pm 91.20$ & $215.08 \pm 59.31$ & $229.83 \pm 94.60$ & 0.600 & $234.59 \pm 81.12$ & $216.68 \pm 125.64$ & 0.615 \\
\hline$A L T, U / L$ & $24.50(13.75-40.25)$ & $24.50(10.75-39.75)$ & $24.50(14.00-41.75)$ & 0.654 & $25.00(13.00-40.50)$ & $24.00(14.00-42.50)$ & 0.883 \\
\hline AST, U/L & $22.50(15.00-32.25)$ & $21.50(15.50-27.50)$ & $23.00(15.25-35.25)$ & 0.460 & $20.00(14.50-52.00)$ & $24.00(15.50-46.00)$ & 0.313 \\
\hline$C K, U / L(n=105)$ & $76.09 \pm 40.77$ & $84.58 \pm 34.67$ & $74.99 \pm 41.53$ & 0.227 & $71.31 \pm 36.51$ & $85.00 \pm 52.41$ & 0.268 \\
\hline $\begin{array}{l}\text { CK-MB, ng/mL ( } \mathrm{n}= \\
105)\end{array}$ & $1.95 \pm 4.49$ & $0.67 \pm 0.33$ & $2.12 \pm 4.75$ & 0.083 & $1.08 \pm 1.78$ & $4.95 \pm 8.14$ & $<0.001$ \\
\hline $\mathrm{LDH}, \mathrm{U} / \mathrm{L}$ & $193.00(159.75-241.25)$ & $180.00(157.75-200.25)$ & $196.50(160.75-260.75)$ & 0.214 & $190.00(155.00-235.00)$ & $239.00(182.00-672.80)$ & 0.007 \\
\hline APTT, s & $37.65(35.55-40.70)$ & 36.90 (35.33-39.53) & $37.90(35.60-41.20)$ & 0.440 & $38.30(35.65-41.20)$ & $36.50(32.25-40.50)$ & 0.085 \\
\hline PT, s & $13.40(12.80-13.93)$ & $13.20(12.90-13.68)$ & $13.40(12.83-14.00)$ & 0.321 & $13.40(12.90-14.00)$ & $13.20(11.85-14.30)$ & 0.281 \\
\hline $\mathrm{d}$-dimer, $\mu \mathrm{g} / \mathrm{mL}$ & $0.06(0.05-0.08)$ & $0.22(0.22-0.22)$ & $0.37(0.22-0.81)$ & 0.009 & $0.28(0.22-0.64)$ & $0.70(0.32-1.50)$ & $<0.001$ \\
\hline $\mathrm{FIB}, \mathrm{g} / \mathrm{L}$ & $3.96 \pm 1.60$ & $3.05 \pm 0.54$ & $4.07 \pm 1.65$ & $<0.001$ & $3.78 \pm 1.47$ & $4.89 \pm 1.87$ & 0.001 \\
\hline $\mathrm{Hs}-\mathrm{CRP}, \mathrm{mg} / \mathrm{L}(n=98)$ & $2.30(0.68-8.40)$ & $0.90(0.33-1.83)(86)$ & $2.45(0.98-11.85)$ & 0.008 & $2.25(0.60-8.75)$ & $3.95(2.30-47.80)$ & 0.002 \\
\hline $\mathrm{PCT}, \mathrm{ng} / \mathrm{ml}(n=97)$ & $0.06(0.05-0.08$ & $0.06(0.05-0.07)$ & $0.07(0.05-0.09)$ & 0.121 & $0.06(0.05-0.08)(62)$ & $0.08(0.06-0.30)$ & 0.001 \\
\hline
\end{tabular}

Abbreviation: IL interleukin, TNF tumor necrosis factor, Hs-CRP high-sensitivity C-reactive protein, CT computed tomography, PCT procalcitonin, COVID-19 coronavirus disease 2019, PLT platelet, ALT alanine aminotransferase, AST aspartate aminotransferase, CK creatine kinase, LDH lactic dehydrogenase, APTT activated partial thromboplastin time, PT prothrombin time, FIB fibrinogen

toward increased neutrophil count and activated partial thromboplastin time with the aggravation of the disease severity, but did not reach statistical significance.

\section{Cytokine profiles between COVID-19 without and with pneumonia}

Compared with COVID-19 without pneumonia, COVID-19 with pneumonia had significantly higher serum IL-2R, IL-6, and TNF- $\alpha$. Serum cytokines including IL-2R, IL-6, IL-8, and TNF- $\alpha$.were increased significantly with COVID-19 severity. The cytokine profiles in different groups are showed in the Table 3.

\section{Correlation analysis between lung injury and cytokine in COVID-19 with pneumonia}

We used CT severity score and $\mathrm{PaO}_{2} / \mathrm{FiO}_{2}$ ratio to assess lung injury in COVID-19 patients with pneumonia. Arterial blood gas analysis was not routinely performed in COVID-19 patients. Generally, it was more often performed in more severe COVID-19 patients. In total, 94 COVID-19 patients with pneumonia had the data of CT severity score, and 51 COVID-19 patients with pneumonia had the data of $\mathrm{PaO}_{2} / \mathrm{FiO}_{2}$ ratio. In COVID-19 patients with pneumonia, severe group had significantly higher CT severity score and lower $\mathrm{PaO}_{2} / \mathrm{FiO}_{2}$ than moderate group (Fig. 1). Correlation analysis between

Table 3 The cytokine profile in different groups

\begin{tabular}{|c|c|c|c|c|c|c|c|}
\hline & Overall $(n=106)$ & $\begin{array}{l}\text { COVID-19 without } \\
\text { pneumonia/Mild } \\
(n=12)\end{array}$ & $\begin{array}{l}\text { COVID-19 with } \\
\text { pneumonia }(n=94)\end{array}$ & $p$-values & Moderate $(n=69)$ & Severe $(n=25)$ & $p$-values \\
\hline $\mathrm{IL}-1 \beta, \mathrm{pg} / \mathrm{mL}$ & $5.00(5.00-5.00)$ & $5.00(5.00-5.00)$ & $5.00(5.00-5.00)$ & 0.726 & $5.00(5.00-5.00)$ & $5.00(5.00-5.00)$ & 0.829 \\
\hline $\mathrm{IL}-2 \mathrm{R}, \mathrm{U} / \mathrm{mL}$ & $424.50(268.75-692.75)$ & $260.00(229.25-358.50)$ & $463.50(281.50-716.75)$ & 0.002 & $381.00(266.00-631.00)$ & 725.00 (471.00-968.50) & $<0.001$ \\
\hline IL-6, pg/mL & $3.48(1.63-11.39)$ & $1.85(1.50-2.74)$ & $3.86(1.79-13.60)$ & 0.016 & $2.90(1.59-7.29)$ & $17.05(3.95-120.00)$ & $<0.001$ \\
\hline IL-8, pg/mL & $9.30(6.25-12.48)$ & 7.05 (6.15-11.18) & $9.35(6.45-12.95)$ & 0.223 & $8.90(5.80-12.05)$ & 11.50 (9.05-18.00) & 0.036 \\
\hline IL-10, pg/mL & $5.00(5.00-5.00)$ & $5.00(5.00-5.53)$ & $5.00(5.00-5.00)$ & 0.849 & $5.00(5.00-5.00)$ & $5.00(5.00-6.44)$ & 0.198 \\
\hline $\begin{array}{l}\text { TNF-a, pg/ } \\
\mathrm{mL}\end{array}$ & $7.60(6.10-9.70)$ & $6.35(5.43-7.15)$ & 7.95 (6.28-9.95) & 0.016 & 7.50 (6.10-9.70) & $8.70(7.40-11.85)$ & 0.007 \\
\hline
\end{tabular}




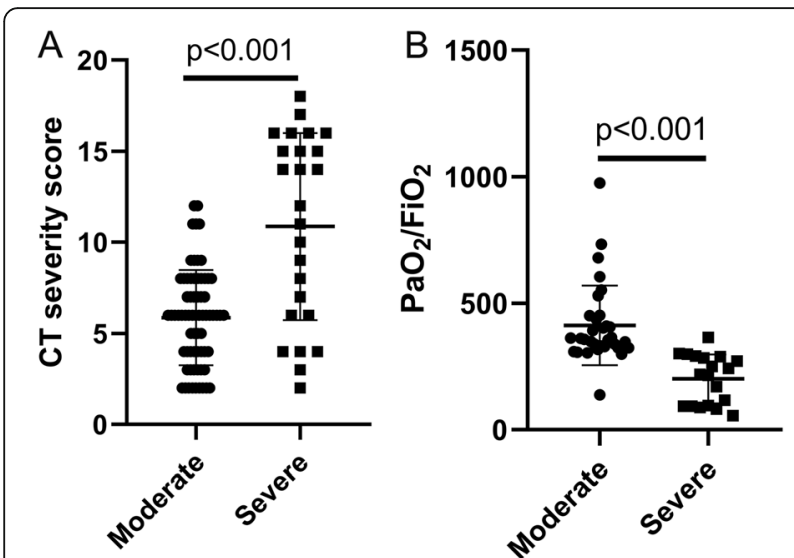

Fig. 1 Comparisons of the $\mathrm{CT}$ severity score and $\mathrm{PaO}_{2} / \mathrm{FiO}_{2}$ between moderate group and severe group (a. CT severity score; b. $\left.\mathrm{PaO}_{2} / \mathrm{FiO}_{2}\right)$

lung injury index and demographic data, laboratory data, as well as cytokines is presented in Table 4. CT severity score and $\mathrm{PaO}_{2} / \mathrm{FiO}_{2}$ were significantly correlated with age, presence of any coexisting disorder, lymphocyte count, PCT, IL-2R, and IL-6. IL-8 was significantly correlated with $\mathrm{PaO}_{2} / \mathrm{FiO}_{2}$, but not with $\mathrm{CT}$ severity score. The correlations between cytokines and CT severity score, $\mathrm{PaO}_{2} / \mathrm{FiO}_{2}$ are showed in Figs. 2 and 3, respectively.

Table 4 Spearman rank correlation coefficients between lung injury ( $\mathrm{CT}$ severity score and $\mathrm{PaO}_{2} / \mathrm{FiO}_{2}$ ) and demographic data, laboratory data, and cytokines

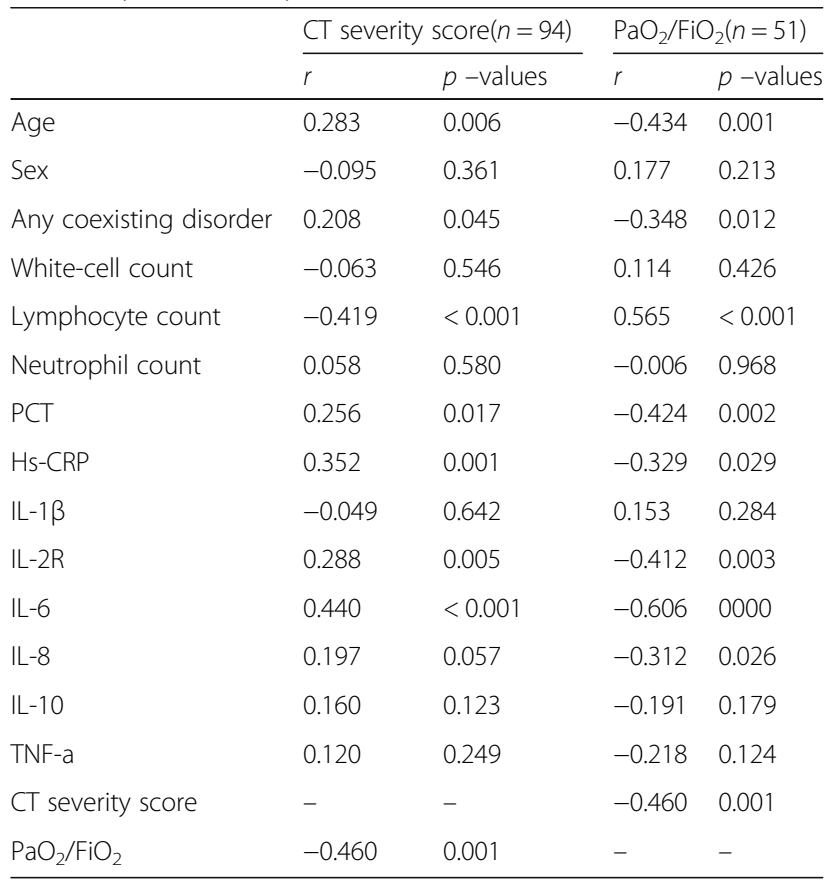

Abbreviation: IL interleukin, TNF tumor necrosis factor, $\mathrm{Hs}$-CRP high-sensitivity C-reactive protein, $C T$ computed tomography, $P C T$ procalcitonin
Predictors of lung injury in COVID with pneumonia

Stepwise multiple linear regression analyses were used to evaluate independent variables associated with $\mathrm{CT}$ severity score and $\mathrm{PaO}_{2} / \mathrm{FiO}_{2}$. The variables with statistical significance in Table 4 were taken as candidates for further stepwise multiple linear regression analyses. Independent variables including age, presence of any coexisting disorder, lymphocyte count, log IL-6, log IL-8, $\log \mathrm{IL}-2 \mathrm{R}, \log \mathrm{PCT}$ and $\log \mathrm{hs}-\mathrm{CRP}$ were entered into the regression model, and $\mathrm{CT}$ severity score was taken as dependent variable. The results showed that only log IL- 6 was included in the final model $(\beta=0.397$, adjusted $\left.\mathrm{r}^{2}=0.147, p<0.001\right)$. When $\mathrm{PaO}_{2} / \mathrm{FiO}_{2}$ was taken as dependent variable, the analysis identified the log IL- 6 as the only independent explanatory variables for $\mathrm{PaO}_{2} /$ $\mathrm{FiO}_{2}\left(\beta=-0.434\right.$, adjusted $\left.\mathrm{r}^{2}=0.169, p=0.003\right)$.

\section{Discussion}

Main findings of this retrospective study are as follows: 1. COVID-19 patients with pneumonia had higher levels of IL-2R, IL-6, and TNF- $\alpha$ than COVID-19 patients without pneumonia. 2. Both IL-2R and IL-6 were statistically correlated with the severity of lung injury accessed by CT severity score and $\mathrm{PaO}_{2} / \mathrm{FiO}_{2}$ in COVID-19 patients with pneumonia.3. IL-6 was the independent predictor of the severity of lung injury in COVID patients with pneumonia after controlling for confounders. The findings of this study highlight the role of cytokines in mediating lung injury in COVID-19 pneumonia.

Cytokine storm is characterized by excessive inflammatory reaction in which proinflammatory cytokines are increasingly released in response to microbial infection. The process can result in tissue injury and an unfavorable prognosis in infectious disease [8]. This phenomenon has been noted in COVID-19 [9] as well as other coronavirus disease such as SARS [10] and MERS [11]. ALI/acute respiratory distress syndrome (ARDS) is a common consequence of a cytokine storm in systemic circulation and the lung alveolar environment [11]. As early as 2004, Wong et al. [12] found that SARS patients had marked elevation of Th1 cytokine interferon (IFN)gamma, inflammatory cytokines IL-1, IL-6 and IL-12 for at least 2 weeks after disease onset. Another study focusing on the cytokine profiles in MERS patients found that the severe group had significantly higher serum levels of IL- 6 and CXCL-10 than the mild group, which suggested that IL-6 and CXCL-10 were elevated in MERS patients who developed severe diseases [13].

Some researchers have noticed the cytokine responses associated with SARS-CoV-2 infection and investigated the cytokine profiles in COVID-19 patients. Huang et al. [4] found that ICU COVID-19 patients had higher plasma levels of cytokine profiles than those in non-ICU 


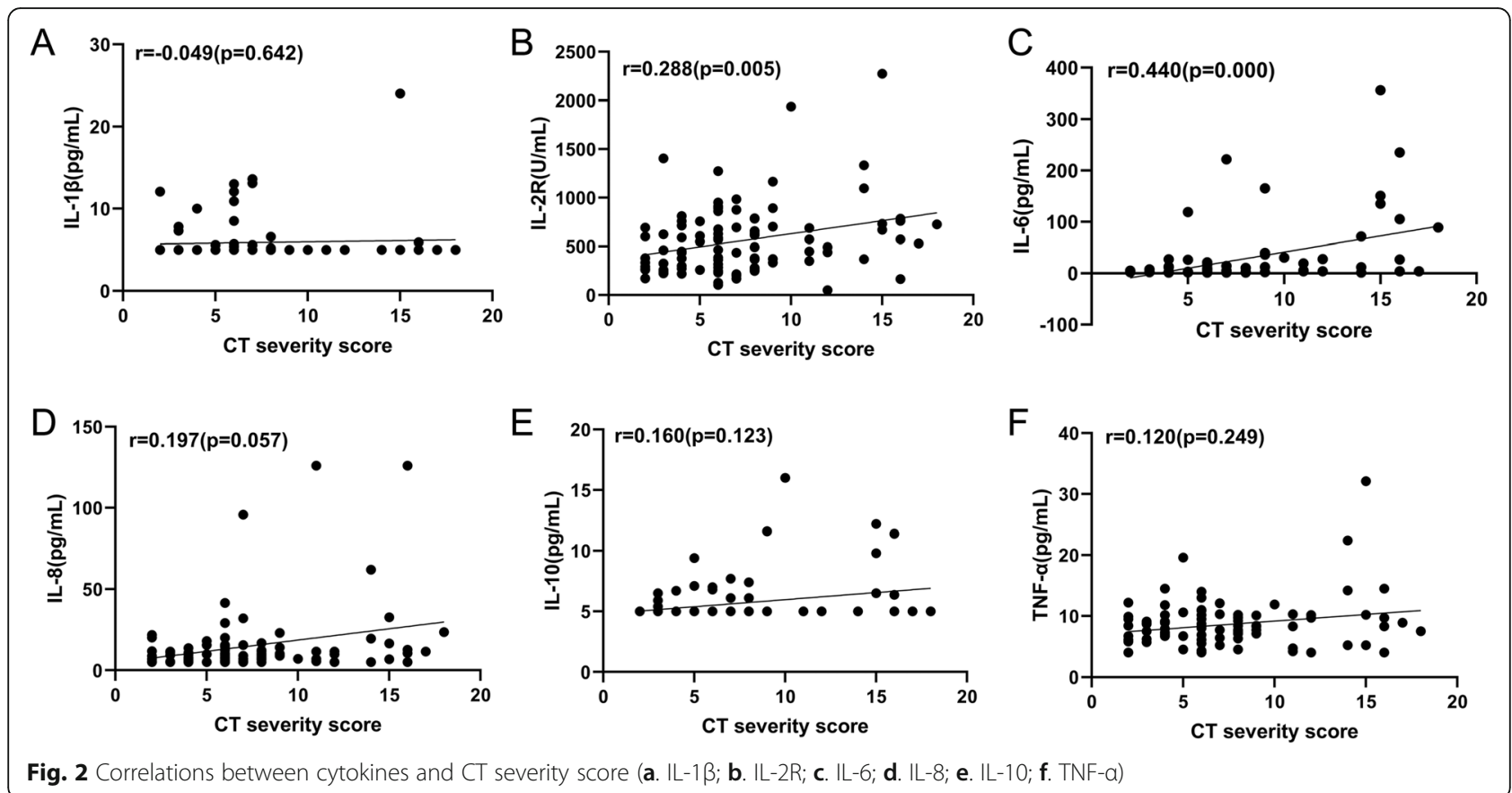

COVID-19 patients. Hou et al. [14] showed that lymphocytes were significantly decreased while cytokines including IL-8, TNF- $\alpha$, IL-2R, IL-10 and IL-6 were significantly increased with increased severity of COVID-19. SARS-CoV-2 infection could result in injury to multiple organs leading to multiorgan failure. Previous studies mainly focused on the relationship between cytokines profiles and the severity of COVID-19, which was characterized by a respiratory and systemic infectious disease. Lung was the main targeted organ during SARS-CoV-2 infection and ARDS was the most important cause of COVID-19 death. Therefore, we aimed to evaluate the role of cytokines in lung injury in COVID19 patients and attempted to find out a potential therapeutic target for the management lung injury in COVID-19 pneumonia.

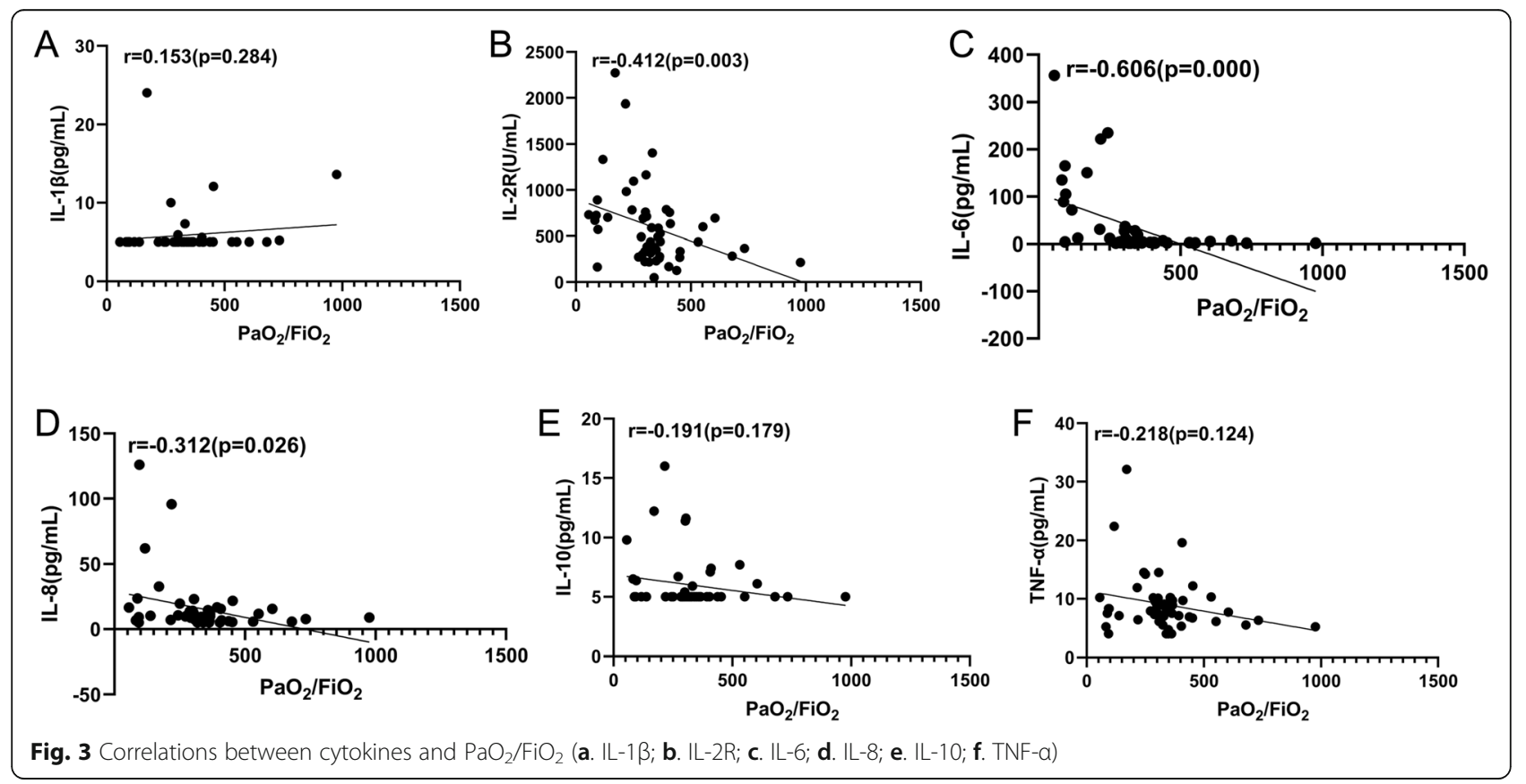


In this study, $\mathrm{CT}$ severity score and $\mathrm{PaO}_{2} / \mathrm{FiO}_{2}$ were used to evaluate extent of lung lesions and hypoxemia respectively. These two indexes were chosen based on the murray score [15], which is used to characterize the severity of lung injury. We revealed that COVID-19 patients with pneumonia had significantly higher levels of serum IL-2R, IL-6, and TNF- $\alpha$ than COVID-19 patients without pneumonia. This result indicated that the elevation of cytokines was significantly associated with presence of COVID-19 pneumonia. Then we further analyzed data of patients with COVID-19 pneumonia and found that both serum IL-2R and IL- 6 were statistically correlated with the severity of lung injury. The findings suggested that cytokines play an important role in the lung injury in COVID-19 pneumonia. We noted that lymphocyte count was positively correlated with $\mathrm{PaO}_{2} / \mathrm{FiO}_{2}$ in COVID-19 patients with pneumonia. This was supported by a previous study, which showed that the lower lymphocyte count was commonly seen in COVID-19 patients and was significantly correlated with disease severity. The results of flow cytometry showed that the lower lymphocyte count in COVID-19 was largely attributed to the decrease in number of $\mathrm{T}$ lymphocytes including CD4+ T cells and CD8+ T cells [5]. Our results indicated that the COVID-19 pneumonia patients with significantly lower lymphocyte count should be closely monitored due to higher risk of respiratory failure and ARDS.

The results of the present study have some clinical implications. We found that IL- 6 was the independent predictor of the severity of lung injury in COVID patients with pneumonia after controlling for confounders. The findings directly provide the evidence supporting the favorable outcomes of IL-6R blockers tocilizumab treatment in COVID-19 patients. Tocilizumab can specifically block IL- 6 from binding to the soluble and membrane-bound IL-6R and inhibit signal transduction of inflammatory process [16]. It has been suggested as a treatment of COVID-19 [17]. A study included 25 severe COVID-19 patients who received tocilizumab therapy reported that tocilizumab was associated with dramatic decline in inflammatory markers, radiological improvement and reduced ventilatory support requirements [18]. Another study retrospectively analyzing the outcomes of tocilizumab treatment in 21 severe and critical COVID19 patients showed that tocilizumab was associated with immediate improvement of the symptoms, hypoxygenmia, and CT opacity changes in most of the patients [19]. Our results, together with other study findings, suggest that IL- 6 could serve as a useful marker to guide tocilizumab therapy in COVID-19. It also can be used to predict the efficacy of tocilizumab therapy in COVID-19. Targeted therapy based on IL-6 level may be helpful to alleviate lung injury in COVID-19 pneumonia and decrease mortality. SARS-CoV-2 infection can lead to injury of multiple organs, it will be interesting to explore whether IL-6 in systemic circulation mediates other organ or tissue injury in COVID-19. Future studies are needed to clarify this issue.

Several limitations of this study should be considered when interpreting results. Firstly, the sample size of the present study was relatively small, especially the number of patients in the group of COVID-19 without pneumonia was limited; thus statistical non-significance may occur because of insufficient power. Secondly, the study was a retrospective design, which might result in some biases (eg, unclear records, incomplete data). Thirdly, there was not any critical ill case in the present study, which might restrict the generalizability of the results to critical ill COVID-19 patients. Fourthly, only 6 cytokines which are assumed to play crucial roles in COVID-19 pneumonia were evaluated. Other cytokines, which may also play important roles in infectious diseases were not measured in the present study..

\section{Conclusions}

Our study showed that elevation of circulating cytokines was significantly associated with presence of pneumonia in COVID-19 and the severity of lung injury in COVID19 pneumonia. Circulating IL-6 independently predicted the severity of lung injury in COVID-19 pneumonia. The findings of our study could help to better understand the role of cytokines in COVID-19 associated lung injury and highlight a potential therapeutic target for the management lung injury in COVID-19 pneumonia.

\section{Abbreviations}

COVID-19: Coronavirus disease 2019; SARS-CoV-2: Severe acute respiratory syndrome coronavirus 2; CT: Computed tomography; IL: Interleukin; WHO: World Health Organization; SARS: Severe acute respiratory syndrome; MERS: Middle east respiratory syndrome; ICU: Intensive care unit; TNF: Tumor necrosis factor; hs-CRP: High-sensitivity C-reactive protein; PCT: Procalcitonin; ALI: Acute lung injury; ARDS: Acute respiratory distress syndrome; IFN: Interferon

\section{Acknowledgements}

Not applicable.

\section{Authors' contributions}

LDC, ZYZ, XJW and XBZ conceived and designed the study, analyzed the data and drafted this manuscript. YQC, WZY, MHW and QFH contributed to analysis of the data, and revising of the manuscript. All authors have read and approved the final manuscript.

\section{Funding}

This work was supported by Youth Research Fund from Fujian Provincial Health Bureau (2018-2-65), and Natural Science Foundation of Fujian Province (2018 J01393). The sponsor had no role in study design, study conduction, data collection, data analysis, data interpretation, or writing of the report.

\section{Availability of data and materials}

All data generated or analyzed during this study are included in this published article. 


\section{Ethics approval and consent to participate}

This retrospective study was approved by the Ethics Committee of Zhongshan Hospital, Xiamen University. All subjects gave signed informed consent.

\section{Consent for publication}

Not applicable.

\section{Competing interests}

The authors declare that they have no known competing financial interests or personal relationships that could have appeared to influence the work reported in this paper.

\section{Author details}

'Department of Respiratory and Critical Care Medicine, Zhangzhou Affiliated Hospital of Fujian Medical University, Zhangzhou, Fujian Province, China. ${ }^{2}$ Department of Geriatrics, Zhongshan Hospital, Xiamen University; Teaching Hospital of Fujian Medical University, Xiamen, Fujian, China. ${ }^{3}$ Department of Pulmonary and Critical Care Medicine, Fujian Third People's Hospital, Fuzhou, Fujian, China. ${ }^{4}$ Department of Pulmonary and Critical Care Medicine, Zhongshan Hospital, Xiamen University; Teaching Hospital of Fujian Medical University, No. 201, Hubin Nan Road, Siming District, Xiamen, Fujian Province 361004, People's Republic of China.

Received: 23 May 2020 Accepted: 23 July 2020

Published online: 29 July 2020

\section{References}

1. Yao XH, Li TY, He ZC, Ping YF, Liu HW, Yu SC, Mou HM, Wang LH, Zhang HR, Fu WJ, et al. A pathological report of three COVID-19 cases by minimally invasive autopsies. Zhonghua Bing Li Xue Za Zhi. 2020;49(0):E009.

2. Shimabukuro-Vornhagen A, Godel P, Subklewe M, Stemmler HJ, Schlosser HA, Schlaak M, Kochanek M, Boll B, von Bergwelt-Baildon MS. Cytokine release syndrome. J Immunother Cancer. 2018;6(1):56.

3. Moore JB, June CH. Cytokine release syndrome in severe COVID-19. Science. 2020;368(6490):473-4.

4. Huang C, Wang Y, Li X, Ren L, Zhao J, Hu Y, Zhang L, Fan G, Xu J, Gu X, et al. Clinical features of patients infected with 2019 novel coronavirus in Wuhan, China. Lancet. 2020;395(10223):497-506.

5. Chen G, Wu D, Guo W, Cao Y, Huang D, Wang H, Wang T, Zhang X, Chen $\mathrm{H}, \mathrm{Yu} \mathrm{H}$, et al. Clinical and immunological features of severe and moderate coronavirus disease 2019. J Clin Invest. 2020;130(5):2620-9.

6. Chung M, Bernheim A, Mei X, Zhang N, Huang M, Zeng X, Cui J, Xu W, Yang Y, Fayad ZA, et al. CT imaging features of 2019 novel coronavirus (2019-nCoV). Radiology. 2020;295(1):202-7.

7. Li K, Fang Y, Li W, Pan C, Qin P, Zhong Y, Liu X, Huang M, Liao Y, Li S. CT image visual quantitative evaluation and clinical classification of coronavirus disease (COVID-19). Eur Radiol. 2020:30(8):4407-16.

8. Tisoncik JR, Korth MJ, Simmons CP, Farrar J, Martin TR, Katze MG. Into the eye of the cytokine storm. Microbiol Mol Biol Rev. 2012;76(1):16-32.

9. Sun X, Wang T, Cai D, Hu Z, Chen J, Liao H, Zhi L, Wei H, Zhang Z, Qiu Y, et al. Cytokine storm intervention in the early stages of COVID-19 pneumonia. Cytokine Growth Factor Rev. 2020;53:38-42.

10. Huang KJ, Su IJ, Theron M, Wu YC, Lai SK, Liu CC, Lei HY. An interferongamma-related cytokine storm in SARS patients. J Med Virol. 2005;75(2):18594.

11. Channappanavar R, Perlman S. Pathogenic human coronavirus infections: causes and consequences of cytokine storm and immunopathology. Semin Immunopathol. 2017:39(5):529-39.

12. Wong CK, Lam CW, Wu AK, Ip WK, Lee NL, Chan IH, Lit LC, Hui DS, Chan $\mathrm{MH}$, Chung SS, et al. Plasma inflammatory cytokines and chemokines in severe acute respiratory syndrome. Clin Exp Immunol. 2004;136(1):95-103.

13. Kim ES, Choe PG, Park WB, Oh HS, Kim EJ, Nam EY, Na SH, Kim M, Song KH, Bang $\mathrm{JH}$, et al. Clinical progression and cytokine profiles of Middle East respiratory syndrome coronavirus infection. J Korean Med Sci. 2016;31(11): $1717-25$.

14. Hou H, Zhang B, Huang H, Luo Y, Wu S, Tang G, Liu W, Mao L, Mao L, Wang $F$, et al. Using IL-2R/lymphocytes for predicting the clinical progression of patients with COVID-19. Clin Exp Immunol. 2020;201(1):76-84.

15. Murray JF, Matthay MA, Luce JM, Flick MR. An expanded definition of the adult respiratory distress syndrome. Am Rev Respir Dis. 1988;138(3):720-3.
16. Jones SA, Scheller J, Rose-John S. Therapeutic strategies for the clinical blockade of IL-6/gp130 signaling. J Clin Invest. 2011;121(9):3375-83.

17. Fu B, Xu X, Wei H. Why tocilizumab could be an effective treatment for severe COVID-19? J Transl Med. 2020;18(1):164.

18. Alattar R, Ibrahim TBH, Shaar SH, Abdalla S, Shukri K, Daghfal JN, Khatib MY, Aboukamar M, Abukhattab M, Alsoub HA, et al. Tocilizumab for the treatment of severe coronavirus disease 2019. J Med Virol. 2020. https://doi. org/10.1002/jmv.25964.

19. Xu X, Han M, Li T, Sun W, Wang D, Fu B, Zhou Y, Zheng X, Yang Y, Li X, et al. Effective treatment of severe COVID-19 patients with tocilizumab. Proc Natl Acad Sci U S A. 2020;117(20):10970-5.

\section{Publisher's Note}

Springer Nature remains neutral with regard to jurisdictional claims in published maps and institutional affiliations.
Ready to submit your research? Choose BMC and benefit from:

- fast, convenient online submission

- thorough peer review by experienced researchers in your field

- rapid publication on acceptance

- support for research data, including large and complex data types

- gold Open Access which fosters wider collaboration and increased citations

- maximum visibility for your research: over $100 \mathrm{M}$ website views per year

At BMC, research is always in progress.

Learn more biomedcentral.com/submissions 